Article

\title{
Antifungal Activity and Phytochemical Screening of Vernonia amygdalina Extract against Botrytis cinerea Causing Gray Mold Disease on Tomato Fruits
}

\author{
Siti Fairuz Yusoff ${ }^{1,2}$, Farah Farhanah Haron ${ }^{3}$, Mahmud Tengku Muda Mohamed ${ }^{1}$, \\ Norhayu Asib ${ }^{4}$, Siti Zaharah Sakimin ${ }^{1}$, Faizah Abu Kassim ${ }^{2}$ and Siti Izera Ismail ${ }^{4, *}$ ] \\ 1 Department of Crop Science, Faculty of Agriculture, Universiti Putra Malaysia, Serdang 43400, Selangor, \\ Malaysia; yuezyusoff@gmail.com (S.F.Y.); mtm59@gmail.com (M.T.M.M.); szaharah@upm.edu.my (S.Z.S.) \\ 2 Agricultural Science Department, Faculty of Technical and Vocational, Universiti Pendidikan Sultan Idris, \\ Tanjong Malim 35900, Perak, Malaysia; faizah@ftv.upsi.edu.my \\ 3 Pest and Disease Management Programme, Horticulture Research Centre, Malaysian Agricultural Research \\ and Development Institute, Serdang 43400, Selangor, Malaysia; farahfarhanah@mardi.gov.my \\ 4 Department of Plant Protection, Faculty of Agriculture, Universiti Putra Malaysia, Serdang 43400, Selangor, \\ Malaysia; norhayuasib@upm.edu.my \\ * Correspondence: izera@upm.edu.my; Tel.: +603-97694851
}

Received: 30 July 2020; Accepted: 9 September 2020; Published: 11 September 2020

\begin{abstract}
Gray mold disease caused by Botrytis cinerea is a damaging postharvest disease in tomato plants, and it is known to be a limiting factor in tomato production. This study aimed to evaluate antifungal activities of Vernonia amygdalina leaf extracts against $B$. cinerea and to screen the phytochemical compound in the crude extract that had the highest antifungal activity. In this study, crude extracts of hexane, dichloromethane, methanol, and water extracts with concentration levels at $100,200,300,400$, and $500 \mathrm{mg} / \mathrm{mL}$ were shown to significantly affect the inhibition of B. cinerea. Among the crude extracts, dichloromethane extract was shown to be the most potent in terms of antifungal activities. The SEM observation proved that the treatment altered the fungal morphology, which leads to fungal growth inhibition. For the in vivo bioassay, the fruits treated with dichloromethane extract at 400 and $500 \mathrm{mg} / \mathrm{mL}$ showed the lowest disease incidence with mild severity of infection. There were 23 chemical compounds identified in V. amygdalina dichloromethane extract using GCMS analysis. The top five major compounds were dominated by squalene (16.92\%), phytol $(15.05 \%)$, triacontane $(11.31 \%)$, heptacosane $(7.14 \%)$, and neophytadiene $(6.28 \%)$. Some of these significant compounds possess high antifungal activities. This study proved that $V$. amygdalina from dichloromethane extract could be useful for inhibiting gray mold disease on tomato fruit and has potential as a natural antifungal agent.
\end{abstract}

Keywords: Vernonia amygdalina; antifungal activity; Botrytis cinerea; phytochemical; tomato; gray mold disease

\section{Introduction}

In Malaysia, approximately $96.30 \%$ of tomato production comes from the highlands, including Lojing, Kelantan, and Cameron Highland, Pahang [1]. The temperatures of these two locations range from 18 to $22{ }^{\circ} \mathrm{C}$, with a relative humidity of $93-95 \%$, which are optimal conditions for the development of fungal pathogen. Botrytis cinerea is a fungal pathogen of gray mold disease that can infect dicotyledonous plants, including tomato. Subjected to scientific and economic importance, B. cinerea was ranked as the second top plant pathogen in the world [2]. In 2015, Tijjani et al. [3] 
observed tomato fruits with gray mold symptoms in postharvest storage at Cameron Highlands with $65 \%$ disease incidence, and this is the first report of gray mold disease on tomato fruits in Malaysia.

B. cinerea infection can develop in the field and can also cause postharvest decay or remain latent until storage. Spore germination of this pathogen grows vigorously in higher relative humidity and low temperature [4]. Thus, in cold storage, it leads to the development of gray mold symptoms, and this disease spreads rapidly among fruits in the same packaging. Chemical fungicides are the most commonly used to control gray mold on tomato fruits, but the repeated use of synthetic fungicide can develop fungal resistance and be harmful to consumer health. A few modes of action from a new fungicide provide adequate protection for fresh tomatoes [5]. However, the residue and toxicity concerns may limit their use.

Among the postharvest strategies in controlling plant diseases, natural products offer a promising treatment to reduce the disease incidence of postharvest diseases. Natural products contain advanced chemical novelty compared to chemically synthesized products, and for this reason, researchers try to discover new bioactive compounds in plants [6]. Plant extracts also contain beneficial secondary metabolites such as phenolics, tannins, coumarins, quinones, flavonoids, saponins, terpenoids, and alkaloids. These compounds have been proven to be potentially significant in plant protection as antimicrobial agents [7]. Many experiments have been conducted using plant extracts to control B. cinerea pathogen, which causes gray mold disease. Soylu et al. [8] found that essential oils extracted from rosemary and lavender could cause hyphae shriveled, protoplast leakage, conidia loss, and cytoplasmic coagulated on B. cinerea morphology. The extracted essential oil of fennel, cinnamon, and anis have also shown fungicidal effects on B. cinerea in in vitro and in vivo tests [9]. Moreover, the extraction of oregano and lemon effectively lowered the disease severity of gray mold disease in tomatoes, strawberries, and cucumbers [10]. In recent findings, stilbene extracted from grapevine leaves possessed antifungal activity of $B$. cinerea by inhibiting the mycelium growth and simultaneously reducing the necrotic lesion [11].

Bitter leaf is scientifically known as Vernonia amygdalina. In Africa and Asia, it is commonly used as a medicinal plant [12]. Various parts of V. amygdalina, including the leaf, root, and stem have been used for their antidiabetic, antioxidant, antimicrobial, anticancer, anti-inflammatory, and antiplasmodial effects [13]. Among the plant parts, researchers identified that the leaf part accumulates the highest chemical constituents and nutritional compositions [14]. Detailed investigations in the compound purification of $V$. amygdalina extract discovered many promising active compounds; for example, flavonoids, triterpenoids, saponins, tannins, sesquiterpene lactones, alkaloids, terpenes, phenolics, and steroidal glycosides [12]. According to Akowuah et al. [15], the extract from V. amygdalina was non-toxic in mice when exposed to up to $2000 \mathrm{mg} / \mathrm{kg} /$ day for 28 days.

To date, most researchers have focused on V. amygdalina crude extract in order to uncover its potential as an antifungal agent for the management of plant disease. Recent findings found that $V$. amygdalina ethanol extracts showed a good ability to inhibit postharvest fungal pathogens Rhizopus stolonifer and Fusarium moniliforme [16,17]. In another study, in an in vitro test using an ethanol crude extract of V. amygdalina at $300 \mathrm{mg} / \mathrm{mL}$, the growth of Cercosporella persica and Curvularia lunatus were completely inhibited [18]. However, there has been no report on the antifungal activity of $V$. amygdalina extracted from different polarities of solvent against $B$. cinerea isolated from tomato. Therefore, this study aimed to (a) evaluate in vitro antifungal activities of $V$. amygdalina crude extract against $B$. cinerea in tomato; (b) study the effect of $V$. amygdalina extract on the morphology of B. cinerea; (c) determine in vivo antifungal activities of V. amygdalina crude extract against $B$. cinerea; and (d) screen the chemical constituents in $V$. amygdalina extract that are responsible for antifungal activities. 


\section{Materials and Methods}

\subsection{Plant Materials}

Mature plants of V. amygdalina were collected from the local supplier in Puchong, Selangor and verified by a botanist from the Biodiversity Unit, Institute of Bioscience, Universiti Putra Malaysia. A voucher specimen (SK 3280/18) was deposited in the herbarium of the same institute. The plants were thoroughly cleaned, and the stems were cut into $25 \mathrm{~cm}$ lengths and planted in Ladang 15, Universiti Putra Malaysia (geographical coordinates: $2^{\circ} 59^{\prime} 19.8^{\prime \prime}$ North, $101^{\circ} 43^{\prime} 50^{\prime \prime}$ East, Malaysia) in December 2017. After two months, approximately $17 \mathrm{~kg}$ of matured leaves were harvested and brought to the Postharvest Laboratory, Universiti Putra Malaysia. The leaves were rinsed under running tap water to remove dirt, shade-dried for one week, and oven-dried at $40{ }^{\circ} \mathrm{C}$ for $4 \mathrm{~h}$. The dried leaves were ground for two minutes using a high-speed grinder. The powdered sample was kept in an airtight container for further extraction processes.

\subsection{Preparation of V. amygdalina Crude Extracts}

The organic solvents in analytical grade (99\% minimum purity) of hexane (Bendosen Laboratory Chemicals, Shah Alam, Malaysia), dichloromethane (DCM, Macron-Fine Chemicals, France), methanol (HmbG Chemicals, Hamburg, Germany), and acetone (Bendosen Laboratory Chemicals, Shah Alam, Malaysia) were used in the crude extraction process. The sequential extractions were performed according to the method as described by Haron et al. [19]. The sequential extraction procedure was shown in Figure 1. Each of the extracts was concentrated in a Buchi rotary evaporator until a sticky dark green crude extract was obtained. The highest percentage of crude extract yield was methanol $(15.34 \%)$, followed by dichloromethane (DCM) $(4.40 \%)$ and hexane $(2.62 \% \mathrm{~g})$. The crude extracts were kept in an airtight jar and stored at $4{ }^{\circ} \mathrm{C}$.

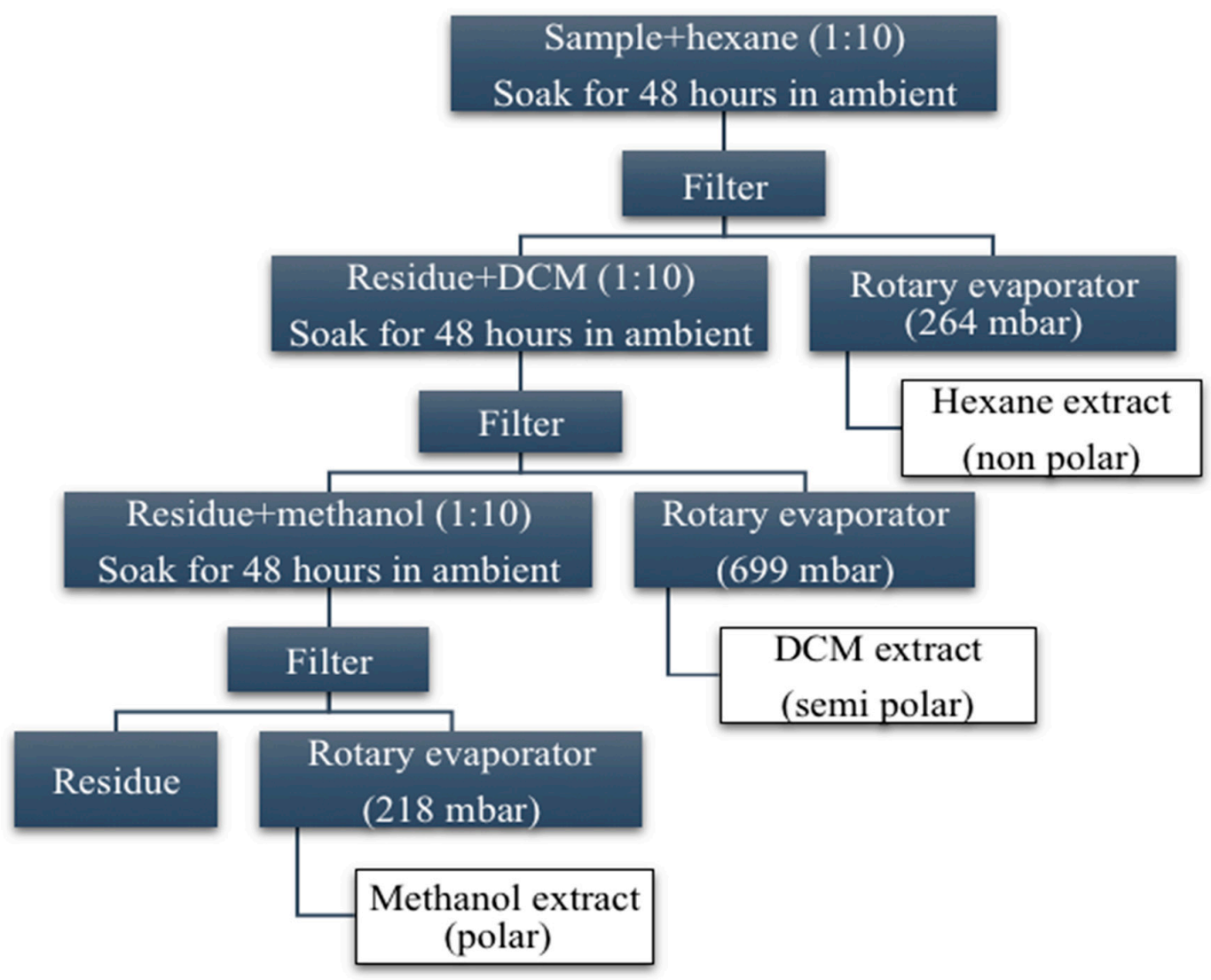

Figure 1. Sequential extraction procedure of V. amygdalina. 
For the aqueous extract, $1 \mathrm{~kg}$ of the sample was soaked in $10 \mathrm{~L}$ of sterile distilled water and sonicated for $30 \mathrm{~min}$ at $50^{\circ} \mathrm{C}$. Then, it was filtered by using filter paper. The filtration was stored at $-80^{\circ} \mathrm{C}$ in a deep freezer (Ultra Low Temperature Freezer DW-86L386, Haier Medical and Laboratory Co., Ltd., Shandong, China). Next, it was freeze-dried in a freeze dryer (Christ Freeze Dryer BETA 1-8LD, Martin Christ Gefriertrocknungsanlagen $\mathrm{GmbH}$, Osterode am Harz, Germany) for three days. The obtained crude extract was ground using a pestle and mortar to obtain a $389.5 \mathrm{~g}$ fine powder and kept at $4{ }^{\circ} \mathrm{C}$ for further use.

\subsection{Preparation of $B$. cinerea}

B. cinerea was isolated from the diseased tomato fruits. The pure culture of the fungus was sub-cultured in potato dextrose agar (PDA) media. The identification of this specific fungus was viewed under a microscope for morphology characteristics. The morphological and molecular characteristics of B. cinerea were similar to the description of Javed et al. [20] and Tijjani et al. [3].

\subsection{In vitro Evaluation for V. amygdalina Antifungal Activity}

The crude extract was dissolved in $1 \mathrm{~mL}$ of acetone and sterilized using $0.4 \mu \mathrm{m}$ syringe filter (Sartorius). Next, the extract solution was mixed with $15 \mathrm{~mL}$ of PDA in a sterile vial. The mixture was vortexed thoroughly and poured into an 85-mm Petri dish. The agar in Petri dishes was allowed to solidify to become poison agar. Poison agar medium was prepared individually at the concentration of 100, 200, 300, 400, and $500 \mathrm{mg} / \mathrm{mL}$ for each crude extract. Mycelial plugs from the pure culture of B. cinerea with 5-mm diameters were transferred to the center of the Petri dish containing PDA. Then, the plates were put into incubator (Model LM-575RD, Yihder Technology Co. LTD, Taipei, Taiwan) and incubated at $20 \pm 2{ }^{\circ} \mathrm{C}$ for eight days to produce full-plate growth of mycelium with conidia. The edge of the active growing fungal plug $(4 \mathrm{~mm})$ from $B$. cinerea was taken and placed at the center of poison agar. The Petri dishes were incubated up to 8 days in an incubator $\left(20^{\circ} \mathrm{C}\right)$, and the fungal growth was observed. The percentage of radial growth $(P I R G)$ was calculated after eight days of incubation as follows.

$$
P I R G=\frac{R 1-R 2}{R 1} \times 100
$$

$R 1$ and $R 2$ are radial growth of fungus for control and extract, respectively.

\subsection{Microscopic Observation Using a Scanning Electron Microscope (SEM)}

The plates that contained the highest in vitro antifungal activities were viewed under SEM to confirm the fungal inhibition. The plugs $(1 \times 1 \mathrm{~cm})$ were harvested from the control and DCM-treated plates, respectively. The sample preparation protocol followed that described by Heckman et al. [21]. Each plug was fixed in $2.5 \%$ glutaraldehyde for five hours at $4{ }^{\circ} \mathrm{C}$. Next, the plugs were washed with $0.1 \mathrm{M}$ sodium cacodylate buffer for three changes of $10 \mathrm{~min}$ each. One percent of osmium tetroxide was used in the post-fixed process for two hours at $4{ }^{\circ} \mathrm{C}$. Then, the plugs were rewashed with $0.1 \mathrm{M}$ sodium cacodylate buffer for three changes of $10 \mathrm{~min}$ each. A series of acetone was applied every 10-min interval in the dehydration process $(35 \%, 50 \%, 75 \%, 95 \%)$ including $100 \%$ acetone for three changes every $15 \mathrm{~min}$. The specimens were transferred into a specimen basket and put into a critical dryer for $1.5 \mathrm{~h}$. After that, all specimens were stuck onto the stub and sputter-coated (Baltec SCD005) with gold in an ion sputter for two minutes. All sample specimens were viewed by microscope examination using JEOL JSM-6400 SEM.

\subsection{Antifungal Activities of V. amygdalina by In Vivo Bioassay}

The fresh and premium quality of tomato fruits in maturity index 3 (green with slight red) was selected. Two hundred of the selected fruits were washed under running tap water and air-dried for two hours. Then, the fruits were sprayed with $70 \%(v / v)$ ethanol and air-dried in laminar flow at ambient temperature for $30 \mathrm{~min}$. Next, 120 fruits were dipped into the three most effective extract solutions 
that showed the highest antifungal activity from in vitro bioassay (DCM at 300, 400, and $500 \mathrm{mg} / \mathrm{mL}$ ) for five minutes. For negative control, 40 fruits were dipped in sterile distilled water and acetone. Meanwhile, another 40 fruits that were dipped in $0.5 \mathrm{~g} / \mathrm{L}$ Kenlate fungicide solution (active ingredient: $50 \% \mathrm{w} / \mathrm{w}$ benomyl) were used as a positive control. All treated fruits were excised using sterile cork borer ( $2 \mathrm{~mm}$ deep and $5 \mathrm{~mm}$ wide) at the equatorial side.

The preparation method of fungal plugs for in vivo bioassay was similar to that for the in vitro bioassay. The fresh fungal plug at $4 \mathrm{~mm}$ was harvested using a cork borer at the outermost layer of mycelium and inserted at the excised treated fruits. Finally, the fruits were kept in plastic boxes ( 40 fruits/box) and stored in ambient temperature at $95 \%$ relative humidity for five days [22]. Each treatment was replicated four times. Each replication consisted of ten fruits, and the experiment was repeated twice. At the end of storage duration, disease incidence and disease severity index (DSI) were determined using the following equations.

$$
\begin{gathered}
\text { Disease incidence }(\%)=\frac{\text { Number of infected fruits }}{\text { Total number of fruit per treatment }} \times 100 \\
D S I=\sum \frac{a \times n}{A B} \times 100
\end{gathered}
$$

where $a=$ disease scale, $n=$ number of fruits in a specific scale, $A=$ highest disease scale, $B=$ total number of fruits.

The disease severity was evaluated based on scale 0 to 4 as described by Rosero-Hernández et al. [23] using the following scale: $0=$ no visible symptoms of fruits (no infection); $1=1-25 \%$ inoculated area covered with slight necrotic and water-soaked lesion (mild infection); $2=26-50 \%$ of the inoculated area covered with necrotic, white to gray mycelia and water-soaked lesion (moderate infection); $3=51-75 \%$ of fruits are necrotic with spore mass appeared and water-soaked (severe infection); $4=>76 \%$ necrotic tissue appears soft, watery and decayed (very severe).

\subsection{Screening for V. amygdalina Chemical Constituents Using Gas Chromatography-Mass Spectrometry (GCMS) Analysis}

The crude samples at $0.02 \mathrm{~g}$ were dissolved in $1 \mathrm{~mL}$ acetone (HPLC grade, Fisher Chemical, USA). The solution was vortexed and filtered using a $0.02 \mu \mathrm{m}$ filter syringe (Sartouris). The sterile crude extract was inserted into the HPLC vial and analyzed using GC-MS QP2010 Ultra (Shimadzu, Kyoto, Japan) comprising a gas chromatograph interfaced with a mass spectrometer. The compound separation was carried out using a Rxi-5MS fused silica capillary column of $30 \mathrm{~m} \times 0.25 \mathrm{~mm}$ internal diameter (di) and $0.25 \mathrm{~mm}$ in film thickness (Restek $\mathrm{GmbH}$, Homburg, Germany). The conditions for analysis were set as follows: column oven temperature was programmed column oven temperature at $50{ }^{\circ} \mathrm{C}$, injection temperature maintained at $250{ }^{\circ} \mathrm{C}$, injection mode split, flow control mode at the pressure of $37.1 \mathrm{kpa}$, total flow of $11.8 \mathrm{~mL} / \mathrm{min}$ at $1 \mathrm{~mL} / \mathrm{min}$, column flow of $0.8 \mathrm{~mL} / \mathrm{min}$, split ratio of 10.0, ion source temperature $200^{\circ} \mathrm{C}$, interface temperature $250^{\circ} \mathrm{C}$, solvent cut time $2.0 \mathrm{~min}$, and detector gain mode by relative and detector gain $0.88 \mathrm{kV}+0.00 \mathrm{kV}$. The column oven temperature was set at $50{ }^{\circ} \mathrm{C}$ (maintained for $3 \mathrm{~min}$ ), raised at $10^{\circ} \mathrm{C} / \mathrm{min}$ to $280{ }^{\circ} \mathrm{C}$ (maintained for $3 \mathrm{~min}$ ), and finally maintained at $300^{\circ} \mathrm{C}$ for $10 \mathrm{~min}$. Mass spectra were taken at the start time of $2.5 \mathrm{~min}$ and end time of $93.0 \mathrm{~min}$. The ACQ mode Scan was carried out at an event time of $0.10 \mathrm{~s}$, with a scan speed of $10,000 \mathrm{~m} / \mathrm{s}$. The start $\mathrm{m} / \mathrm{z}$ was 40 , and the end $\mathrm{m} / \mathrm{z}$ was 700 . Constituents were identified based on data libraries by analyzing and comparing mass spectra (FFNSC1.3.lib, WILEY229.lib and NIST11s.lib).

\subsection{Experimental Design and Statistical Analysis}

For the in vitro bioassay, the experiment was conducted in completely randomized design (CRD) with four replications. The test was arranged in two factorial analysis consisting of 4 types of crude extracts (hexane, DCM, methanol, aqueous) $\times 5$ concentration levels $(100,200,300,400$, and $500 \mathrm{mg} / \mathrm{mL})$. 
For the in vivo bioassay, the experimental design was also in CRD and four replications, thus leading to a total of 80 experiments. The data were analyzed using analysis of variance (ANOVA), and the means were separated using the least significant difference (LSD) test at $p \leq 0.05$. The data analysis was carried out in SAS software (version 9.4).

\section{Results}

\subsection{In Vitro Antifungal Activities of V. amygdalina Crude Extract against B. cinerea}

In this study, PIRG was measured and calculated to determine the antifungal activity of four types of crude extracts at five different concentrations. As shown in Table 1, both the main factors of the crude extracts and the concentration levels significantly inhibited the in vitro growth of $B$. cinerea. There was also a highly significant interaction effect between crude extract and concentration levels $(\mathrm{CE} \times \mathrm{CL})$ on B. cinerea growth.

Table 1. Main and interaction effects of V. amygdalina crude extracts and concentration level on PIRG of B. cinerea. PIRG: percentage of radial growth.

\begin{tabular}{cc}
\hline Factors & PIRG (\%) \\
\hline Crude extracts (CE) & \\
\hline Hexane & $22.65 \pm 2.34 \mathrm{~d}^{\mathrm{x}}$ \\
Dichloromethane & $64.94 \pm 2.19 \mathrm{a}$ \\
Methanol & $45.15 \pm 2.28 \mathrm{~b}$ \\
Aqueous & $25.18 \pm 2.32 \mathrm{c}$ \\
\hline Concentration levels $(\mathrm{mg} / \mathrm{mL})(\mathrm{CL})$ & \\
\hline 100 & $25.07 \pm 4.47 \mathrm{~d}$ \\
200 & $34.04 \pm 4.93 \mathrm{c}$ \\
300 & $40.04 \pm 4.25 \mathrm{~b}$ \\
400 & $48.05 \pm 4.61 \mathrm{a}$ \\
500 & $50.18 \pm 4.29 \mathrm{a}$ \\
Significance & $* *$ \\
CE $\times$ CL & \\
\hline
\end{tabular}

Values are expressed as mean \pm SD. ${ }^{X}$ Means with the same letters within a column and each factor are not significantly different at $p \leq 0.05$ using the LSD test. ${ }^{* *} p \leq 0.01$.

The results indicate that the DCM crude extract of $V$. amygdalina possessed the most potent antifungal activity, exhibiting a fungistatic effect on the growth of $B$. cinerea followed by methanol, aqueous, and hexane crude extract (Figure 2). As expected, higher concentrations of 400 and $500 \mathrm{mg} / \mathrm{mL}$ showed the highest PIRG of B. cinerea for all crude extracts. However, both concentration levels showed no significant differences in $B$. cinerea inhibition growth. The effects of PIRG of $B$. cinerea between methanol crude extract at 200 and $300 \mathrm{mg} / \mathrm{mL}$ as well as hexane crude extract at 100 and $200 \mathrm{mg} / \mathrm{mL}$ were not significant. Within the concentration level of DCM extract, the PIRG increased as the concentration level was raised to $400 \mathrm{mg} / \mathrm{mL}$. This result shows that the maximum inhibitory effects of $B$. cinerea radial growth were DCM at 400 and $500 \mathrm{mg} / \mathrm{mL}$, with $74.85 \%$ and $75.7 \%$ inhibition, respectively. 


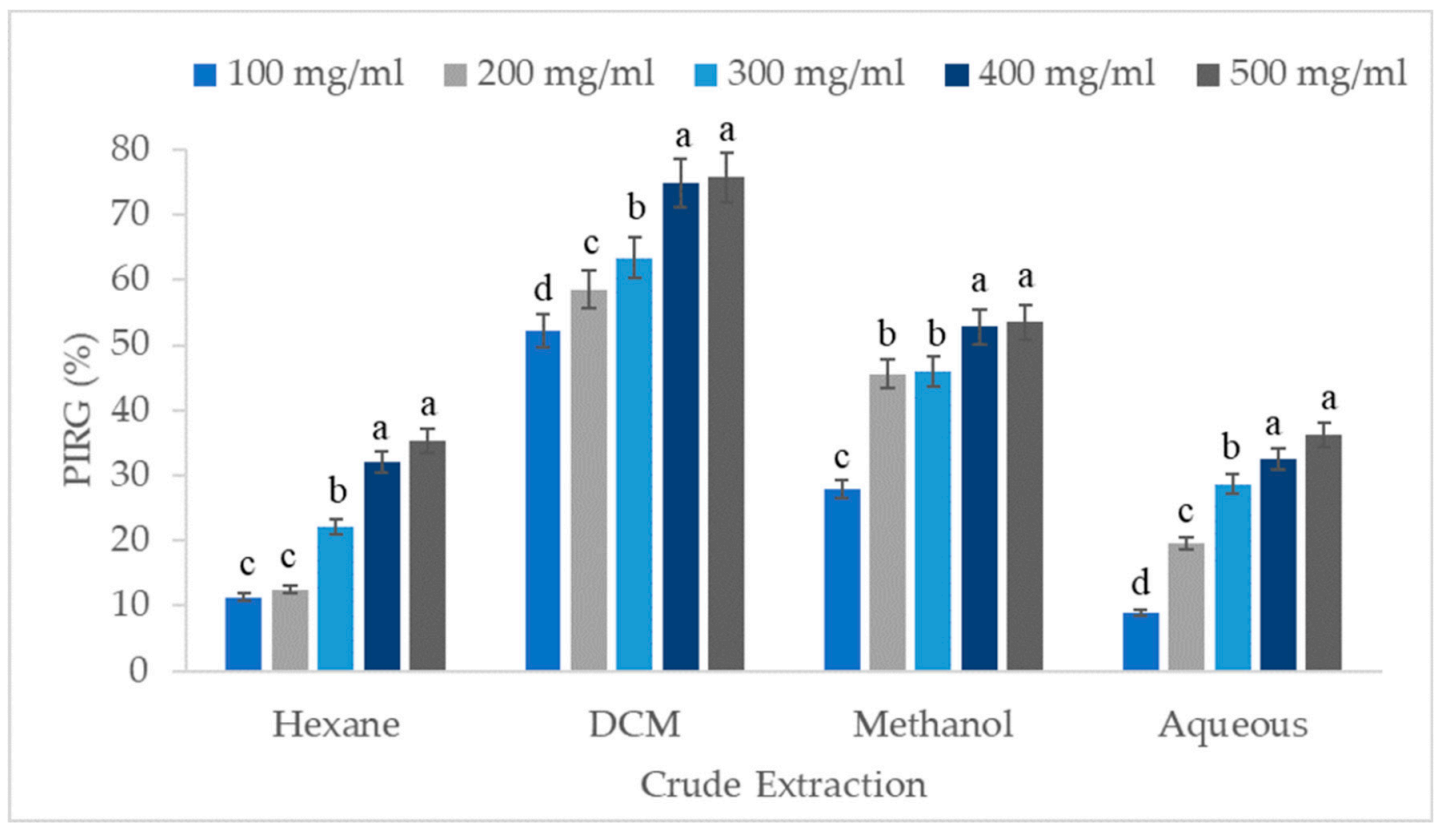

Figure 2. Effect of crude extraction of V. amygdalina at various concentrations on the PIRG of B. cinerea after eight days of incubation. Means with the same letter within each crude extraction are not significantly different at $p \leq 0.05$ using the least significant difference (LSD) test.

\subsection{Effect of V. amygdalina Crude Extract on the Morphology of B. cinerea}

The morphology of B. cinerea was altered after being exposed to V. amygdalina DCM treatment. Under SEM observation, the mycelia of this fungus were shriveled, retarded, and agglutinated while the conidia underwent shrinkage (Figure 3C-F) compared to the control, which had a slender shape, and was massive, and for which the conidiophore was grape-shaped with ellipsoidal conidia (Figure 3A,B).

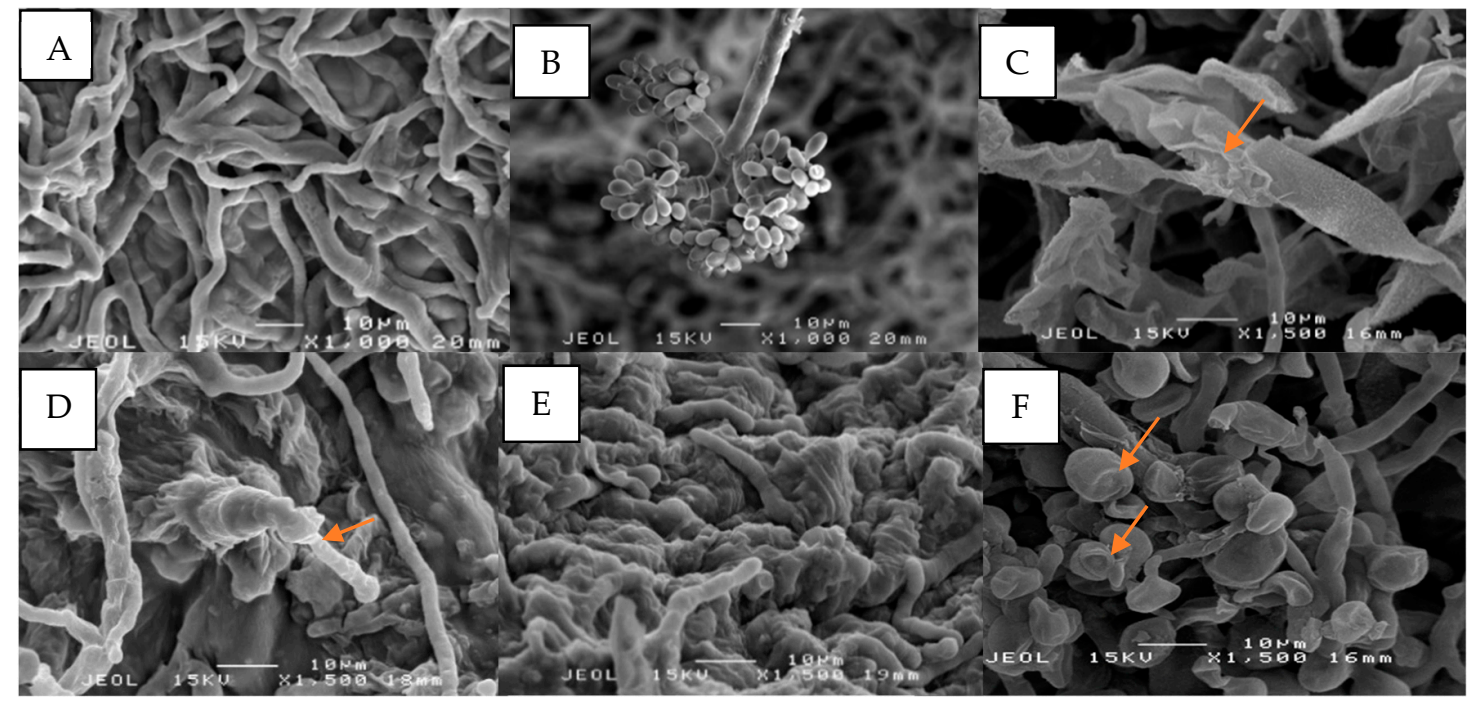

Figure 3. Effects of dichloromethane (DCM) crude extract on B. cinerea at 400 and $500 \mathrm{mg} / \mathrm{mL}$ on mycelium morphology viewed under SEM. (A) Healthy mycelium are slender and uniform, with a smooth surface and an intact structure in the control plate; (B) Healthy conidiophore from the control plate; (C) Mycelia were ruptured, folded with edge burrs, and sheet-like structure at $400 \mathrm{mg} / \mathrm{mL}$; (D) The hyphae tip was wrinkled and deformed at $400 \mathrm{mg} / \mathrm{mL}$; (E) Agglutinated mycelia at $500 \mathrm{mg} / \mathrm{mL}$; (F) The conidia were shrunken at $400 \mathrm{mg} / \mathrm{mL}$. 


\subsection{In Vivo Antifungal Activities of V. amygdalina Crude Extract against B. cinerea}

The in vivo experiment showed that all fruits from the negative control were infected with gray mold disease with $100 \%$ of disease incidence (Table 2). Meanwhile, the artificially inoculated tomato fruits that were dipped in V. amygdalina DCM treatment at 400 and $500 \mathrm{mg} / \mathrm{mL}$ had reduced disease incidence of gray mold by $50 \%$ and $53.13 \%$ compared to the control fruits, respectively. However, the effect on the disease incidence at both concentrations was not significantly different.

Table 2. Percentage of B. cinerea incidence on tomato treated fruits.

\begin{tabular}{cc}
\hline Treatment & Disease Incidence (\%) \\
\hline Negative control & $100 \pm 0.00 \mathrm{a} X$ \\
Benomyl & $68.75 \pm 2.69 \mathrm{~b}$ \\
DCM $300 \mathrm{mg} / \mathrm{mL}$ & $60.41 \pm 2.69 \mathrm{c}$ \\
DCM $400 \mathrm{mg} / \mathrm{mL}$ & $50.0 \pm 3.40 \mathrm{~d}$ \\
DCM $500 \mathrm{mg} / \mathrm{mL}$ & $46.88 \pm 3.13 \mathrm{~d}$ \\
\hline
\end{tabular}

Values are expressed as mean $\pm \mathrm{SD} .{ }^{\mathrm{X}}$ Means with the same letters are not significantly different at $p \leq 0.05$ using the LSD test.

Artificially inoculated tomato that was treated with V.amygdalina DCM extract showed significantly lower disease incidence compared to the commercial fungicide (benomyl) treatment. Regarding the DCM treatments, DCM at $400 \mathrm{mg} / \mathrm{mL}$ could reduce incidence by $2.23 \%$ compared with DCM at $300 \mathrm{mg} / \mathrm{mL}$.

Among the infected fruits, the disease severity displayed a different pattern according to the treatment. Table 3 indicated that the fruits in negative control were observed $27.28 \%$ in disease severity index, with a value of 2 for severity scale and moderate infection category. The necrotic tissue in control fruits was covered with white to gray mycelia and water-soaked lesions.

Table 3. Percentage of disease severity index on tomato treated fruits.

\begin{tabular}{cc}
\hline Treatment & DSI (\%) \\
\hline Negative control & $27.28 \pm 0.29 \mathrm{a} X$ \\
Benomyl & $10.84 \pm 0.69 \mathrm{~b}$ \\
DCM $300 \mathrm{mg} / \mathrm{mL}$ & $4.50 \pm 0.53 \mathrm{c}$ \\
DCM $400 \mathrm{mg} / \mathrm{mL}$ & $2.27 \pm 0.12 \mathrm{~d}$ \\
DCM $500 \mathrm{mg} / \mathrm{mL}$ & $2.19 \pm 0.05 \mathrm{~d}$
\end{tabular}

Values are expressed as mean $\pm \mathrm{SD}$. ${ }^{\mathrm{X}}$ Means with the same letters are not significantly different at $p \leq 0.05$ using the LSD test.

The tomato fruits that were treated with V. amygdalina DCM extract at concentration $300-500 \mathrm{mg} / \mathrm{mL}$ with severity scale 1 were shown to have a significantly lower percentage of disease severity compared to chemical fungicide (benomyl). Thus, the treatment of V. amygdalina DCM extract could be an alternative fungicide, constituting a natural antifungal agent against the gray mold disease of tomato fruits. However, nonetheless, the gray mold disease severity of all treated fruits of DCM extract treatments and benomyl constituted a mild infection.

\subsection{Phytochemical Screening of DCM Crude Extract}

GCMS analyses of the crude extract led to the identification of 23 chemical constituents in the DCM crude extract of V. amygdalina (Figure 4). 


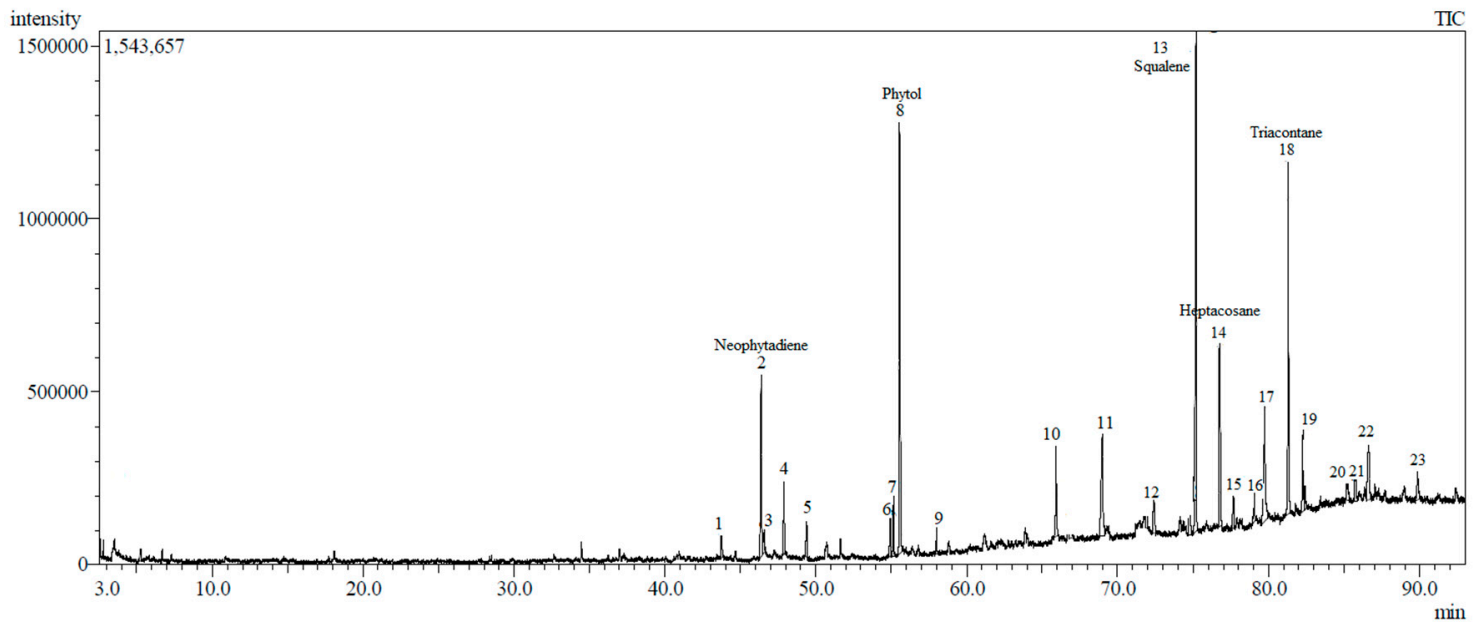

Figure 4. Ion chromatogram of DCM crude extract using GCMS.

The identified compounds are arranged according to their elution order on silica capillary columns. The extract contains a complex mixture consisting of mainly triterpenoid, diterpene alcohol, sesquiterpene, and hydrocarbon lipid. The top five major compounds are squalene (16.92\%), phytol $(15.05 \%)$, triacontane $(11.31 \%)$, heptacosane $(7.14 \%)$, and neophytadiene $(6.28 \%)$ (Table 4$)$.

Table 4. Chemical composition in DCM crude extract of V. amygdalina.

\begin{tabular}{|c|c|c|c|c|}
\hline Peak & Retention Index $* *$ & Compound Name & Chemical Group & Area (\%) \\
\hline 1 & 1763 & Loliolide & Monoterpenoid hydroxylactones & 0.76 \\
\hline 2 & 1839 & Neophytadiene & Sesquiterpene & 6.28 \\
\hline 3 & 1841 & Phytone & Terpene ketone & 0.90 \\
\hline 4 & 1860 & 2-Hexadecen-1-ol & Acyclic diterpene & 0.79 \\
\hline 5 & 1882 & 3,7,11,15-tetramethyl-2-hexadecen-1-ol & Acyclic diterpene & 1.46 \\
\hline 6 & 1966 & Hexadecanoic acid & Fatty acid & 1.06 \\
\hline 7 & 2089 & 9,12-Octadecadienoic acid & Fatty acid & 1.19 \\
\hline 8 & 2119 & Phytol & Diterpene alcohol & 15.05 \\
\hline 9 & 2147 & Linolenic acid & Fatty acid & 1.86 \\
\hline 10 & 2499 & 1-caryophyllene & Bicyclic sesquiterpene & 3.35 \\
\hline 11 & 2577 & $\gamma$-Elemene & Sesquiterpene & 5.72 \\
\hline 12 & 2711 & 1,3,7-Nonatriene- 1 & Monoterpene & 1.35 \\
\hline 13 & 2830 & Squalene & Triterpene & 16.92 \\
\hline 14 & 2892 & Heptacosane & Hydrocarbon lipid & 7.14 \\
\hline 15 & 2577 & Geranyl linalool & Monoterpenoid & 1.12 \\
\hline 16 & 2993 & Tetratriacontane & Hydrocarbon lipid & 1.02 \\
\hline 17 & 3021 & Unknown & $-\quad 1$ & 6.41 \\
\hline 18 & 3097 & Triacontane & Hydrocarbon lipid & 11.31 \\
\hline 19 & 3139 & $\alpha$-Tocopherol & Vitamin E & 6.04 \\
\hline 20 & 3272 & Stigmasterol & Stigmastane & 0.98 \\
\hline 21 & 3290 & $\alpha$-spinasterol acetate & Stigmastane & 1.37 \\
\hline 22 & 3295 & Chondrillasterol & Triterpene (sterol) & 2.90 \\
\hline 23 & 3472 & $\alpha$-tocopherol acetate & Vitamin E & 1.46 \\
\hline
\end{tabular}

** Retention index on the Rxi-5MS silica capillary column.

The other characteristic constituents of the crude extract are loliolide, phytone, 2-hexadecen-1-ol, 3,7,11,15-tetramethyl-2-hexadecen-1-ol, hexadecanoic acid, 9,12-octadecadienoic acid, linolenic acid, caryophyllene, $\gamma$-elemene, 1,3,7-nonatriene-1, geranyl linalool, tetratriacontane, $\alpha$-tocopherol, stigmasterol, $\alpha$-spinasterol acetate, chondrillasterol, $\alpha$-tocopherol acetate, and one unknown compound were found to be minor components of DCM V. amygdalina leaves extract in the present study. Chemical residue of solvents used in the extraction was not found by GCMS analysis. 


\section{Discussion}

Extraction methods involve the separation of the active compound of plant tissues from inactive components using selective solvents. During extraction, solutions defuse into solid plant material and solubilize compounds with similar polarity. The present experiments showed that extracts obtained from $V$. amygdalina contain essential components for the inhibition of mycelial growth of $B$. cinerea pathogenic on tomato plants. However, each of the crude extracts was varied in terms of their antifungal activities. Among the crude extract, DCM extract (semi-polar) of V. amygdalina showed the most potent inhibition on B. cinerea growth. As reported in other cases [24], DCM extract fraction of Pseudognaphalium robustum reduced the in vitro mycelial growth of $B$. cinerea at $45.5 \mu \mathrm{g} / \mathrm{mL}$ by $50 \%$. They stated that it also affected the conidial germination of the $B$. cinerea by reducing oxygen consumption and interrupting plasma membrane integrity.

In contrast, Righini et al. [25] found that the water extract of Anabaena sp., Ecklonia sp., and Jania sp. inhibited the in vitro growth of $B$. cinerea at $2.5,5.0$, and $10.0 \mathrm{mg} / \mathrm{mL}$. Generally, it appears that the inhibitory effect of the plant extracts varies depending on the specific plant and solvent used with no specific trend related to the polarity of the solvent. The usage of different solvent systems will extract a diversity of molecules with distinct polarities. For instance, methanol tends to extract a diversity of compound groups such as polyphenols, glycosides, and flavonoids [26], which can contribute to the fungal inhibitory effect of the extract. DCM and hexane tend to extract mainly semi-polar and nonpolar constituents such as terpenoids, fats, and fatty acid [27]. It would appear that both polar and nonpolar constituents contributed to the antifungal activity of the plant extracts.

The percentage of fungal inhibition in amended PDA medium was also dependent on concentration, and the most significant reduction in mycelial growth was obtained with the highest concentration of crude extract. A similar result was observed by other researchers using ethanol leaf extract of V. amygdalina against tomato diseases [16]. This could be due to the level of composition antifungal compounds obtained from the crude extract. The inhibitory effect of DCM extract increased as the concentration increased, showing more than $50 \%$ growth inhibition at all concentrations. However, the inhibition growth of $B$. cinerea showed no significant difference in any crude extract at concentrations of $400 \mathrm{or} 500 \mathrm{mg} / \mathrm{mL}$. A possible reason for this circumstance is the low water solubility of the antifungal compounds, which limits the miscibility in the agar medium through the poison agar method. Meanwhile, the hydrocarbon components either remained on the medium surface or evaporated, depending on its nature. According to Krzyśko-Łupicka et al. [28], the biocidal action from the plant extract also depends on the chemical composition, concentration, and phytopathogenic fungi strains.

In vivo experimental results show that negative control fruits were 100\% infected with gray mold disease with a severity value of 2 . The necrotic tissue in negative control fruits was water-soaked and covered with fungal mycelia. The highest Botrytis incidence was observed in tomatoes six days after inoculation [29], and in kiwi seven days post-inoculation [30]. Meanwhile, the artificially inoculated tomato fruits that were dipped with the two highest concentrations of DCM extract resulted in the highest reduction in disease incidence of gray mold. The possible reason for these results is the concentration level of antifungal compounds from plant extract being sufficient to control the inoculum of $B$. cinerea on tomato fruits. This statement is supported by the disease severity of gray mold on tomato in the present study, which only causes a mild infection on the fruits. The results provide baseline information for the potential use of the crude extract in the treatment of postharvest gray mold disease. This was necessary because this disease was a latent field infection [31]. However, the treatment data we obtained did not prevent the onset of gray mold disease because the percentage of disease incidence reduction was not $100 \%$, although it was generally low. Fillinger and Elad [32] suggested that B. cinerea is very challenging to control due to its broad host range, different mode infection, and both asexual and sexual stages enabling it to survive in favorable or unfavorable conditions.

Meanwhile, it is well known that the fungicide activity of benomyl on a broad spectrum of phytopathogenic fungi was due to its ability to be absorbed by the phytopathogen cells. However, the present study found that benomyl treatment on $B$. cinerea has a fungistatic activity. Benomyl has 
been applied as a systemic fungicide since 1970 and was used to control B. cinerea in 1971 [33]. Methyl 2-benzimidazole carbamate (MBC) is the major metabolite of benomyl and is primarily responsible for the fungitoxicity. Hammerschlag and Sisler [34] indicated that the primary metabolites were inhibited by the synthesis of DNA, interrupted fungal cell division, and inhibited cytokinesis. However, in this case, the benomyl treatment failed to act as a fungicidal. This could be due to the fungal resistance to this fungicide, since benomyl has been used for many years.

In the present study, the highest antifungal activity of DCM extract against $B$. cinerea could be associated with the presence of 23 bioactive compounds identified using GCMS. The major compounds were dominated by squalene $(16.92 \%)$, phytol $(15.05 \%)$, triacontane $(11.31 \%)$, heptacosane $(7.14 \%)$, and neophytadiene $(6.28 \%)$. Squalene is the most abundant in this crude extract. It is a naturally occurring triterpenoid and a precursor for the synthesis of secondary metabolites such as sterols, hormones, or vitamins. Squalene has been shown to have excellent antioxidant, anticancer, antibacterial, and antifungal biological activities [35]. In pharmacognosy, squalene is extensively used as an excipient for disease management and therapy [36]. Gnamusch et al. [37] found that squalene at high concentration resulted in disturbances in the fungus cellular membranes and interfered with essential membrane functions. The non-toxic chemical nature of lipids makes them excellent carriers as well as their ability to permeate the cell membrane of fungus due to their lipidic nature.

Phytol is the second-highest compound in this extract. It was classified in the diterpene group. Haque and co-workers [38] explained that terpenoids from the plant extract reduce the mitochondrial content of fungus, which could alter the ATP generation and level of reactive oxygen species. Consequently, the mitochondria of the fungus become dysfunctional. Yoshihiro et al. [39] reported that diterpene of phytol could disrupt the cell membranes of the fungus, resulting in $\mathrm{K}+$ ions leaking from the cells, and causing the fungus hyphae to wither.

The aliphatic hydrocarbons of triacontane (n-C30) and heptacosane (n-C27) are identified as major components in this extract. Both long-chain alkanes were found on the surface of plant parts and in abundance in the epicuticular wax of matured leaves [40]. They acted as a physical barrier on the plant in terms of water loss, irradiation, phytopathogen attack, and insect herbivores. The appearance of the epidermal wax of the V. amygdalina leaf surface was proven by Eltahir and AbuEReish [41]. They reported that under SEM observation, the epidermal wax is present in large quantities at the abaxial leaf part compared to the adaxial part. Yin et al. [42] found that the hydrocarbon waxes inhibited Alternaria rot of pear by stunting the spore germination and mycelial growth of Alternaria alternata. However, to date, the specific mechanisms of action of these hydrocarbon compounds as antifungal agents against phytopathogenic fungi have been less reported.

Neophytadiene is a sesquiterpene compound and was found to be a significant component in DCM extract. Neophytadiene is an active compound with antibacterial, antifungal, antipyretic, and antioxidant activities [43]. This sesquiterpene compound could pass through the cell wall, interrupt the cell membrane function, and destroy the fungal mitochondria structure [44]. In a previous study, the sesquiterpene compound isolated from Magnolia grandiflora was also proven to have fungicidal effects against A. alternata and F. culmorium [45]. Neophytadiene extracted from Daucus carota subsp. sativus was identified as a major compound and showed protective as well as preventive activity against $B$. cinerea in strawberry [46].

On the other hand, some of the chemical constituents that appear in lower amounts in this extract, such as terpenoid, steroid, and fatty acid, might also contribute to the antifungal activity. Howard et al. [47] stated that $V$. amygdalina contains bioactive sesquiterpene lactones that possess highly antifungal effects. Similarly, Ivanescu et al. [48] explained that the mechanism of biological activity of alkylating sesquiterpene lactones and the nucleophile sulfhydryl group in proteins led to the disruption of cell function that caused cell wall damage of the fungus. It is possible that the minor chemical constituents might also be related to synergism effects with major compounds, inhibiting B. cinerea growth. 
The mechanism action of antifungal compounds of the $V$. amygdalina extract on the fungal inhibition was observed under SEM. The hyphae of $B$. cinerea exposed to the phytochemical compounds of $V$. amygdalina extract revealed alterations in the hyphal morphology. The mycelia became twisted and folded with a jagged edge. Some mycelia were agglutinated, with withered hyphae tips. Another important observation was the shrinkage of conidia after the treatment. This could prevent the dispersion of the gray mold disease of fruits to the adjacent fruits, since the asexual spores of $B$. cinerea are abundant and easily dispersed by wind or water. The morphology alteration of fungus was related to the secondary metabolites from the plant extract that acted as antifungal substances to restrict the fungal growth [49]. This mode of action was called antibiosis. The antibiosis happened when the secondary metabolites from the plant extract inhibited or restricted the growth of the pathogen. The secondary metabolites inhibited fungal growth through cell membrane disruption, cell wall synthesis inhibition, mitochondrial dysfunction, cell division inhibition, protein synthesis inhibition, and efflux pump inhibition [32]. In this case, the composition of major antifungal compounds, including squalene, phytol and neophytadiene, as well as minor antifungal compounds, acted as synergistic effects in controlling the B. cinerea development.

\section{Conclusions}

This study provides evidence that V. amygdalina extracts of DCM at 400 and $500 \mathrm{mg} / \mathrm{mL}$ had the highest antifungal activities against $B$. cinerea through in vitro and in vivo bioassays. The treatment altered the fungal morphology and inhibited fungal growth. The chemical constituents in this plant extract have the potential to be a natural antifungal agent. Thus, we propose an alternative disease management strategy using V. amygdalina extract to control gray mold disease on tomato. However, further research is necessary to elucidate the mechanism of action and develop the formulation to improve its efficacy and stability for use in postharvest disease control. The postharvest quality study should also involve a formulation application to make sure the quality of fresh fruits is optimal and that the fruits are safe to consume.

Author Contributions: Conceptualization, S.F.Y. and S.I.I.; methodology, S.F.Y., S.I.I. and M.T.M.M.; software, S.F.Y.; validation, S.F.Y., S.I.I. and N.A.; formal analysis, S.F.Y. and S.Z.S.; investigation, S.F.Y.; resources, F.F.H.; data curation, S.F.Y. and S.I.I.; writing-original draft preparation, S.F.Y. and F.A.K.; writing-review and editing, S.F.Y. and S.I.I.; visualization, S.F.Y.; supervision, S.I.I.; project administration, S.I.I.; funding acquisition, S.I.I. All authors have read and agreed to the published version of the manuscript.

Funding: This research was funded by Fundamental Research Grant Scheme (FRGS), from Ministry of Higher Education Malaysia, grant number 5540210.

Acknowledgments: The authors gratefully acknowledge Malaysian Agricultural Research and Development Institute (MARDI) and Universiti Pendidikan Sultan Idris (UPSI) for research facilities.

Conflicts of Interest: The authors declare no conflict of interest. The funder had no role in the design of the study; in the collection, analyses, or interpretation of data; in the writing of the manuscript, or in the decision to publish the results.

\section{References}

1. Department of Agriculture (DOA). Vegetables and Cash Crops Statistic; Department of Agriculture: Kuala Lumpur, Malaysia, 2018.

2. Dean, R.; Van Kan, J.A.; Pretorius, Z.A.; Hammond-Kosack, K.E.; Di Pietro, A.; Spanu, P.D.; Foster, G.D. The Top10 fungal pathogens in molecular plant pathology. Mol. Plant Pathol. 2012, 13, 414-430. [CrossRef] [PubMed]

3. Tijjani, A.; Ismail, S.I.; Khairulmazmi, A.; Dzolkhifli, O. First report of gray mold rot disease on tomato (Solanum lycopersicum L.) caused by Botrytis cinerea in Malaysia. J. Plant Pathol. 2018, 101, 207. [CrossRef]

4. Leyronas, C.; Duffaud, M.; Parès, L.; Jeannequin, B.; Nicot, P.C. Flow of Botrytis cinerea inoculum between lettuce crop and soil. Plant Pathol. 2015, 64, 701-708. [CrossRef]

5. Shridhar, B.P.; Sharma, M.; Gupta, S.K.; Sharma, S.K. New generation fungicides for the management of buckeye rot of tomato. Indian Phytopathol. 2018, 71, 621-625. [CrossRef] 
6. Ma, T.; Luo, J.; Tian, C.; Sun, X.; Quan, M.; Zheng, C.; Kang, L.; Zhan, J. Influence of technical processing units on chemical composition and antimicrobial activity of carrot (Daucus carrot L.) juice essential oil. Food Chem. 2015, 170, 394-400. [CrossRef]

7. Compean, K.L.; Ynalvez, R.A. Antimicrobial activity of plant secondary metabolites: A review. Res. J. Med. Plant. 2014, 8, 204-213.

8. Soylu, E.M.; Kurt, S.; Soylu, S. In vitro and in vivo antifungal activities of the essential oils of various plants against tomato grey mould disease agent Botrytis cinerea. Int. J. Food. Microbiol. 2010, 143, 183-189. [CrossRef]

9. Mohammadi, S.; Aroiee, H.; Aminifard, M.H.; Jahanbakhsh, V. In vitro and in vivo antifungal activates of the essential oils of various plants against strawberry grey mould disease agent Botrytis cinerea. Arch. Phytopathol. Plant Prot. 2012, 45, 2474-2484. [CrossRef]

10. Vitoratos, A.; Bilalis, D.; Karkanis, A.; Efthimiadou, A. Antifungal activity of plant essential oils against Botrytis cinerea, Penicillium italicum and Penicillium digitatum. Not. Bot. Horti Agrobot. 2013, 41, 86-92. [CrossRef]

11. De Bona, G.S.; Adrian, M.; Negrel, J.; Chiltz, A.; Klinguer, A.; Poinssot, B.; Héloir, M.; Angelini, E.; Vincenzi, S.; Bertazzon, N. Dual mode of action of grape cane extracts against Botrytis cinerea. J. Agric. Food Chem. 2019, 67, 5512-5520. [CrossRef]

12. Alara, O.R.; Abdurahmana, N.H.; Mudalipa, S.K.A.; Olalerea, O.A. Phytochemical and pharmacological properties of Vernonia amygdalina: A review. J. Chem. Eng. Ind. Biotech. 2017, 2, 96.

13. Kadiri, O.; Olawoye, B. Vernonia amygdalina: An underutilized vegetable with nutraceutical Potentials-A Review. Turk. J. Agric. Food Sci. Technol. 2016, 4, 763-768. [CrossRef]

14. Toyang, N.J.; Verpoorte, R. A Review of the Medicinal Potentials of Plants of the Genus Vernonia (Asteraceae). J. Ethnopharmacol. 2013, 146, 681-723. [CrossRef]

15. Akowuah, G.A.; May, L.L.Y.; Chin, J.H. Toxicological evaluation of Vernonia amygdalina methanol leaves extracts in rats. Orient. Pharm. Exp. Med. 2015, 15, 365-369. [CrossRef]

16. John, W.C.; Anyanwu, N.C.J.; Ayisa, T. Evaluation of the Effects of the Extract of Vernonia amygdalina on Fungi Associated with Infected Tomatoes (Lycopersicon esculentum) in Jos North Local Government Area, Plateau State, Nigeria. Annu. Res. Rev. Biol. 2016, 9, 1. [CrossRef]

17. Okey, E.N.; Akwaji, P.I.; Akpan, J.B.; Umana, E.J.; Bassey, G.A. In vitro control of tomato (Solanum lycopersicon L.) fruit rot caused by fungi using two plant extracts. Int. Lett. Nat. Sci. 2016, 52, 19-27. [CrossRef]

18. Ilondu, E.M. Phytochemical composition and efficacy of ethanolic leaf extracts of some Vernonia species against two phytopathogenic fungi. J. Biopestic. 2013, 6, 165-172.

19. Haron, F.F.; Sijam, K.; Omar, D.; Rahmani, M. Bioassay-guided isolation of antifungal plumericin from Allamanda species (Apocynaceae). J. Biol. Sci. 2013, 13, 158-162.

20. Javed, S.; Javaid, A.; Anwar, W.; Majeed, R.A.; Akhtar, R.; Naqvi, S.F. First report of Botrytis bunch rot of grapes caused by Botrytis cinerea in Pakistan. Plant Dis. 2017, 101, 1036. [CrossRef]

21. Heckman, C.; Kanagasundaram, S.; Cayer, M.; Paige, J. Preparation of cultured cells for scanning electron microscope. Protoc. Exch. 2007. Available online: https://protocols.scienceexchange.com/protocols/ preparation-of-cultured-cells-for-scanning-electron-microscope (accessed on 25 July 2020).

22. Wang, C.; Zhang, J.; Chen, H.; Fan, Y.; Shi, Z. Antifungal activity of eugenol against Botrytis cinerea. Trop. Plant Pathol. 2010, 35, 137-143. [CrossRef]

23. Rosero-Hernández, E.D.; Moraga, J.; Collado, I.G.; Echeverri, F. Natural Compounds That Modulate the Development of the Fungus Botrytis cinerea and Protect Solanum lycopersicum. Plants 2019, 8, 111. [CrossRef] [PubMed]

24. Cotoras, M.; Mendoza, L.; Muñoz, A.; Yáñez, K.; Castro, P.; Aguirre, M. Fungitoxicity against Botrytis cinerea of a flavonoid isolated from Pseudognaphalium robustum. Molecules 2011, 16, 3885-3895. [CrossRef]

25. Righini, H.; Baraldi, E.; García Fernández, Y.; Martel Quintana, A.; Roberti, R. Different Antifungal Activity of Anabaena sp., Ecklonia sp., and Jania sp. against Botrytis cinerea. Mar. Drugs 2019, 17, 299. [CrossRef] [PubMed]

26. Rauha, J.P.; Remes, S.; Heinonen, M.; Hopia, A.; Ka“hko“nen, M.; Kujala, T.; Pihlaja, K.; Vuorela, H.; Vuorela, P. Antimicrobial effects of Finnish plant extracts containing flavonoids and other phenolic compounds. Int. J. Food Microbiol. 2000, 56, 3-12. [CrossRef]

27. Tiwari, P.; Kumar, B.; Kaur, M.; Kaur, G.; Kaur, H. Phytochemical screening and extraction: A review. Int. Pharm. Sci. 2011, 1, 98-106. 
28. Krzyśko-Łupicka, T.; Walkowiak, W.; Białoń, M. Comparison of the Fungistatic Activity of Selected Essential Oils Relative to Fusarium graminearum Isolates. Molecules 2019, 24, 311.

29. Zhu, Z.; Tian, S. Resistant responses of tomato fruit treated with exogenous methyl jasmonate to Botrytis cinerea infection. Sci. Hortic. 2012, 142, 38-43. [CrossRef]

30. Hua, C.; Li, Y.; Wang, X.; Kai, K.; Su, M.; Zhang, D.; Liu, Y. The effect of low and high molecular weight chitosan on the control of gray mold (Botrytis cinerea) on kiwifruit and host response. Sci. Hortic. 2019, 246, 700-709. [CrossRef]

31. Barkai-Golan, R. Postharvest Diseases of Fruits and Vegetables. Development and Control; Elsevier Science B.V.: Amsterdam, The Netherlands, 2001.

32. Fillinger, S.; Elad, Y. Botrytis-the Fungus, the Pathogen and Its Management in Agricultural Systems; Springer: New York, NY, USA, 2016.

33. Evans, E. Systemic fungicides in practice. Pestic. Sci. 1971, 2, 192-196. [CrossRef]

34. Hammerschlag, R.S.; Sisler, H.D. Benomyl and methyl-2-benzimidazolecarbamate (MBC): Biochemical, cytological and chemical aspects of toxicity to Ustilago maydis and Saccharomyces cerevisiae. Pestic. Biochem. Physiol. 1973, 3, 42-54. [CrossRef]

35. Reddy, L.H.; Couvreur, P. Squalene: A natural triterpene for use in disease management and therapy. Adv. Drug Deliv. Rev. 2009, 61, 1412-1426. [CrossRef] [PubMed]

36. Lozano-Grande, M.A.; Gorinstein, S.; Espitia-Rangel, E.; Dávila-Ortiz, G.; Martínez-Ayala, A.L. Plant sources, extraction methods, and uses of squalene. Int. J. Agron. 2018. [CrossRef]

37. Gnamusch, E.; Ryder, N.S.; Paltauf, F. Effect of squalene on the structure and function of fungal membranes. J. Dermatol. Treat. 1992, 3, 9-13. [CrossRef]

38. Haque, E.; Irfan, S.; Kamil, M.; Sheikh, S.; Hasan, A.; Ahmad, A.; Lakshmi, V.; Nazir, A.; Mir, S.S. Terpenoids with antifungal activity trigger mitochondrial dysfunction in Saccharomyces cerevisiae. Microbiology 2016, 85, 436-443. [CrossRef]

39. Yoshihiro, I.; Toshiko, H.; Shiraishi, A.; Hirose, K.; Hamashima, H.; Kobayashi, S. Biphasic effects of geranylgeraniol, teprenone and phytol on the growth of Staphylococcus aureus. Antimicrob. Agents Chemother. 2005, 49, 1770-1774.

40. Bhattacharjee, I.; Ghosh, A.; Chowdhury, N.; Chatterjee, S.K.; Chandra, G.; Laskar, S. n-Alkane profile of Argemone mexicana leaves. Z. Naturforsch. C 2010, 65, 533-536. [CrossRef]

41. Eltahir, A.S.; AbuEReish, B.I. Microscopical Studies on the leaf and petiole of Vernonia amygadlina Del. Adv. Appl. Sci. Res. 2011, 2, 398-406.

42. Yin, Y.; Bi, Y.; Chen, S.; Li, Y.; Wang, Y.; Ge, Y.; Ding, B.; Li, Y.; Zhang, Z. Chemical composition and antifungal activity of cuticular wax isolated from Asian pear fruit (cv. Pingguoli). Sci. Hortic. 2011, 129, 577-582. [CrossRef]

43. Kumbum, S.; Sivarao, S. Antibacterial, antioxidant activity and GC-MS analysis of Eupatorium odoratum. Asian J. Pharm. Clin. Res. 2012, 5, 12.

44. Freiesleben, S.; Jäger, A. Correlation between plant secondary metabolites and their antifungal mechanisms-a review. Med. Aromat. Plants 2014, 3, 1-6.

45. Ahmed, S.M.; Abdelgaleil, S.A. Antifungal activity of extracts and sesquiterpene lactones from Magnolia grandiflora L. (Magnoliaceae). Int. J. Agric. Biol. 2005, 7, 638-642.

46. Tabet Zatla, A.; Dib, M.E.A.; Djabou, N.; Ilias, F.; Costa, J.; Muselli, A. Antifungal activities of essential oils and hydrosol extracts of Daucus carota subsp. sativus for the control of fungal pathogens, in particular gray rot of strawberry during storage. J. Essent. Oil Res. 2017, 29, 391-399. [CrossRef]

47. Howard, C.B.; Johnson, W.K.; Pervin, S.; Izevbigie, E.B. Recent perspectives on the anticancer properties of aqueous extracts of Nigerian Vernonia amygdalina. Bot. Targets Ther. 2015, 5, 65-76. [CrossRef] [PubMed]

48. Ivanescu, B.; Miron, A.; Corciova, A. Sesquiterpene lactones from Artemisia genus: Biological activities and methods of analysis. J. Anal. Methods Chem. 2015. [CrossRef]

49. Pusztahelyi, T.; Holb, I.J.; Pócsi, I. Secondary metabolites in fungus-plant interactions. Front. Plant Sci. 2015, 6, 573. [CrossRef]

(C) 2020 by the authors. Licensee MDPI, Basel, Switzerland. This article is an open access article distributed under the terms and conditions of the Creative Commons Attribution (CC BY) license (http://creativecommons.org/licenses/by/4.0/). 